\title{
The ambition of the European Respiratory Journal: chapter 2
}

\author{
Marc Humbert
}

Affiliation: Univ. Paris-Sud, Service de Pneumologie, Hôpital Bicêtre, DHU Thorax Innovation, Assistance Publique Hôpitaux de Paris, Inserm U999, LabEx LERMIT, Le Kremlin Bicêtre, France.

Correspondence: M. Humbert, Service de Pneumologie, Hôpital Bicêtre, Assistance Publique Hôpitaux de Paris, 78, rue du Général Leclerc, 94270 Le Kremlin Bicêtre, France. E-mail: marc.humbertabct.aphp.fr Journal http://ow.ly/qonRz

Last year, in my opening editorial as incoming Chief Editor, I stated that "the ambition of the Journal is [... to be the best possible publication available to help, inform and open new horizons to junior and established healthcare professionals and scientists who have an interest in (respiratory) medicine and science" [1]. At the beginning of 2014, I would like to share with you some thoughts about the future of our Journal.

The Editorial Board recognises that impact factor remains, among other criteria, an important indicator of quality in our academic world [1-3]. In this regard, we were delighted when the Journal's impact factor reached an unprecedented level of 6.355 (fig. 1), underscoring our position among the top publications in the field of respiratory medicine. It is particularly noteworthy that the ERJ has solidified its position in this domain when more than 300 original articles and reviews were published in the Journal in 2012. In our quest to further increase our impact factor over the coming years, we will endeavour both to attract highquality manuscripts in our field and remain selective in our editorial decisions. It is thus likely that the number of articles published per year will decrease slightly. However, the goal of promoting excellent original research from a global worldwide authorship remains a core principle.

In 2013, the ERJ editors have worked very hard to evaluate more than 2000 submissions, but also to prepare the launch of new series that will be published in our pages. Last December, the European Lung Corner was published for the first time; in the future, it will provide regular updates from the European Union on key pulmonary medicine issues $[4,5]$. In the first half of 2014, a Back to Basics section will highlight emerging concepts in physiology, immunology, biology, and experimental medicine and surgery. The first series of new State of the Art articles will be published from the second half of 2014 onwards. Lastly, we will soon be launching a novel From the Museum art series. In this exciting context, our readers have certainly noticed that more editorials $[6-8]$, debates $[9,10]$, perspectives $[11,12]$, statements, guidelines, recommendations [13-16], Assembly reports [17-19], letters and correspondences [20] have been published in our pages, providing a broad range of updated information for our community. Of note, letters and correspondences are now published in an Agora section [20] in which we wish to further highlight original research and debate in our fast-growing field.

As expected, the transition between the last editorial team and the new one has been seamless, thanks to a remarkable group of international Associate Editors, Advisors and Editorial Board members. I would like to highlight here the outstanding commitment of Anh Tuan Dinh-Xuan, former Chief Editor and current Deputy Chief Editor of the ERJ, the tireless support of the ERS Publication Committee, chaired by Wisia Wedzicha, and the hard work of our Publication Office in Sheffield led by Elin Reeves and Neil Bullen.

Received: Oct 222013 | Accepted: Oct 242013

Conflict of interest: Disclosures can be found alongside the online version of this article at www.erj.ersjournals.com 


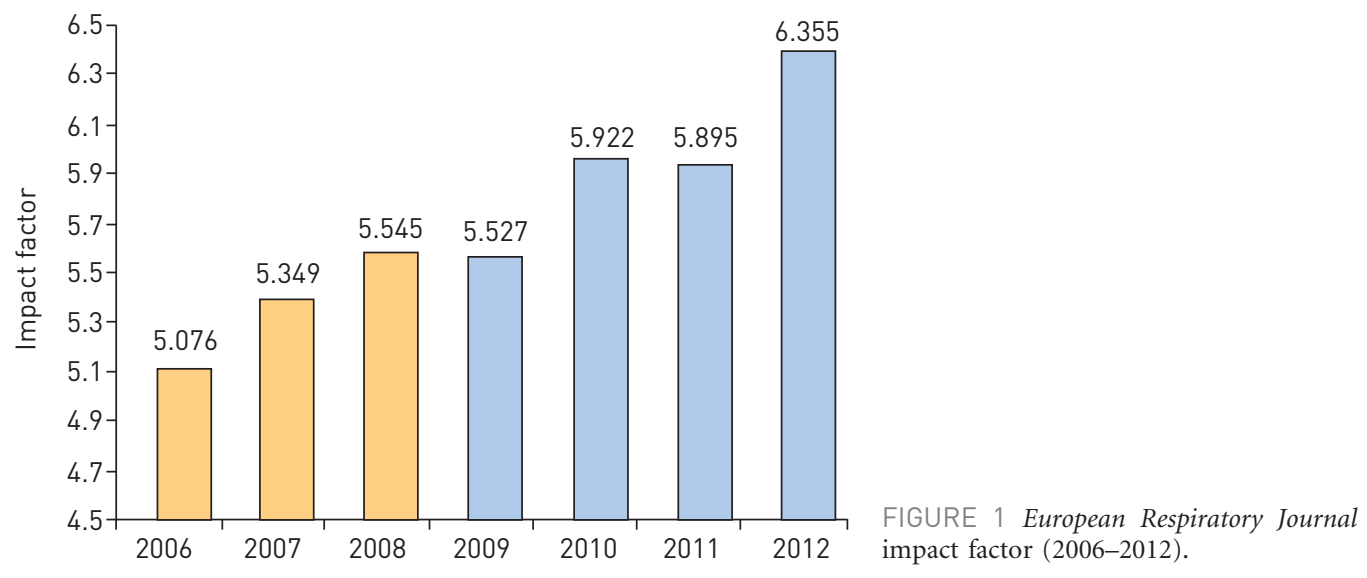

Finally, the editorial staff of the ERJ wishes its readers and authors a happy and prosperous New Year and we look forward to sharing more good news with you all in the future.

\section{References}

Humbert M. The ambition of the European Respiratory Journal. Eur Respir J 2013; 41: 1-2.

2 Dinh-Xuan AT, Brusasco V, Wedzicha JA, et al. ERS publications: the flagship and the fleet. Eur Respir J 2012; 40: 535-537.

3 Dinh-Xuan AT, Brusasco V. The editors' farewell and confident look back to the future. Eur Respir J 2012; 40: 1309-1311.

Sculier JP. The European Lung Corner. Eur Respir J 2013; 42: 1433-1434.

Barry M. Canaries in the coal mine. Eur Respir J 2013; 42: 1469-1471.

Bals R, Ricou Yanmaz J, Schaffter C, et al. The European Respiratory Society fellowship programme: supporting young careers and building networks. Eur Respir J 2013; 42: 564-567.

Blasi F, Barnes PJ, Gaga M, et al. Future directions for the ERS: Presidential plans. Eur Respir J 2013; 42: 875-880. Blasi F, Dara M, van der Werf MJ, et al. Supporting TB clinicians managing difficult cases: the ERS/WHO Consilium. Eur Respir J 2013; 41: 491-494.

Beasley R. Tiotropium Respimat increases the risk of mortality: pro. Eur Respir J 2013; 42: 584-589.

10 Bateman ED. Tiotropium Respimat increases the risk of mortality: con. Eur Respir J 2013; 42: 590-593.

11 Cordier J-F, Cottin V. Neglected evidence in idiopathic pulmonary fibrosis: from history to earlier diagnosis. Eur Respir J 2013; 42: 916-923.

12 Agusti A, Hurd S, Jones P, et al. FAQs about the GOLD 2011 assessment proposal of COPD: a comparative analysis of four different cohorts. Eur Respir J 2013; 42: 1391-1401.

13 Parati G, Lombardi C, Hedner J, et al. Recommendations for the management of patients with obstructive sleep apnoea and hypertension. Eur Respir J 2013; 41: 523-538.

14 Robinson PD, Latzin P, Verbanck S, et al. Consensus statement for inert gas washout measurement using multipleand single- breath tests. Eur Respir J 2013; 41: 507-422.

15 Schraufnagel DE, Blasi F, Kraft M, et al. An official American Thoracic Society and European Respiratory Society policy statement: disparities in respiratory health. Eur Respir J 2013; 42: 906-915.

16 Eber E, Aurora P, Lødrup Carlsen KC, et al. Paediatrics in Amsterdam. Eur Respir J 2012; 40: 215-226.

17 Midulla F, Lombardi E, Lødrup Carlsen KC, et al. Paediatrics in Vienna. Eur Respir J 2013; 42: 1092-1104.

18 Spruit MA, Chavannes NH, Herth FJF, et al. Clinical highlights from the 2011 ERS Congress in Amsterdam. Eur Respir J 2012; 39: 1501-1510.

19 Marvisi M, Herth FJ, Ley S, et al. Selected clinical highlights from the 2012 ERS congress in Vienna. Eur Respir J 2013; 41: 1219-1227.

20 D'Ambrosio L, Tadolini M, Dupasquier S, et al. ERS/WHO Tuberculosis Consilium: reporting of the initial 10 cases. Eur Respir J 2014; 43: 286-289. 